\title{
Prevalence and risk factors of asthma and wheezing among US adults: an analysis of the NHANES III data
}

\author{
A.A. Arif*, G.L. Delclos", E.S. Lee", S.R. Tortolero\#, L.W. Whitehead"
}

Prevalence and risk factors of asthma and wheezing among US adults: an analysis of the NHANES III data. A.A. Arif, G.L. Delclos, E.S. Lee, S.R. Tortolero, L.W. Whitehead. (C) ERS Journals Ltd 2003.

ABSTRACT: The prevalence of asthma has been on the increase in the USA and worldwide. To understand the worsening epidemiological trends of asthma, this study analysed the data from the third National Health and Nutrition Examination Survey (NHANES III) to determine the prevalence and risk factors for asthma and wheezing among US adults.

This analysis used data from 18,825 US adults aged $\geqslant 20$ yrs who had participated in the NHANES III project. After excluding subjects with physician-diagnosed emphysema, a total of 18,393 subjects were included in the final analysis.

The prevalence of current asthma (asthma) was $4.5 \%$ and the prevalence of wheezing in the previous 12 months (wheezing) was 16.4\%. Mexican-Americans exhibited the lowest prevalence of asthma when compared with other race/ethnic groups. Multiple logistic regression analysis showed that Mexican-Americans were less likely to report asthma when compared to non-Hispanic whites. Low education level, female sex, current and past smoking status, pet ownership, lifetime diagnosis of physician-diagnosed hay fever and obesity were all significantly associated with asthma and/or wheezing. No significant effect of indoor air pollutants, as derived from the use of household heating/ cooking appliances, on asthma and wheezing was observed in this study.

In conclusion, this study observed racial/ethnic differences in the prevalence of asthma and wheezing and identified several important risk factors that may contribute to development and/or exacerbation of asthma and wheezing. Contrary to earlier reports, the proxy measures of indoor air pollution used in this study were not found to be associated with increased risk of asthma and wheezing.

Eur Respir J 2003; 21: 827-833.
*The Texas Tech University Health Sciences Center, "The University of Texas-Houston School of Public Health, TX, USA.

Correspondence: A. Arif

The Texas Tech University Health

Sciences Center

Department of Health Services

Research and Management

36014 th Street MS 8161 Lubbock

TX-79430

USA

Fax: 18067431292

E-mail: ahmed.arif@ttmc.ttuhsc.edu

Keywords: Asthma

epidemiology

National Health and Nutrition Examination Survey III

Received: June 242002

Accepted after revision: December 52002
The incidence, prevalence and severity of asthma have been increasing in the general population, both worldwide and in the USA, for the past two decades [1]. There are $\sim 14$ million people in the USA suffering from asthma. The prevalence of self-reported asthma increased by $75 \%$ in the USA from 1980-1994 and the states with the highest prevalence of selfreported asthma were California $(7.1 \%)$ New York $(6.8 \%)$ and Texas $(6 \%)$ [2]. In the largest asthma prevalence survey conducted to date, the European Community Respiratory Health Survey (ECRHS), an overall prevalence of $4.5 \%$ in adults aged 20-44 yrs was found. However, there was considerable variation among the 22 countries studied [3].

In the absence of any gold standard, and because of the variable nature of the disease, accurate case findings of asthma, outside of the clinical setting, is very challenging. A variety of methods have been used in epidemiological surveys to define asthma: self reports of physician-diagnosed asthma $[4,5]$, presence of asthma symptoms, such as wheezing [5], combination of asthma symptoms, e.g. discriminate function predictors [5], or objective measurements like spirometry [6] or use of methacholine or histamine for testing bronchial responsiveness $[5,7]$. Each approach may lead to selection of different study groups with asthma, thereby reporting results that may not be comparable. Although, large-scale epidemiological surveys, such as the ECRHS, have been conducted using nonspecific bronchial challenge [3], the cost and technical skills involved remain a limiting factor in their widespread use. Hence, questionnaire-based self-reports of asthma remain the most commonly used approach for defining asthma in epidemiological surveys.

The National Health and Nutrition Examination Survey (NHANES) provided a rich population-based dataset to identify determinants of asthma and wheezing. This study analysed the data gathered from the third, and most recent, round of the NHANES, to estimate the prevalence and determine the risk factors for adult asthma and wheezing in this population.

\section{Materials and methods}

The National Center for Health Statistics (NCHS) conducts several large-scale surveys to assess the general health status of the USA's general population. Data from the NHANES III, which was conducted by NCHS from 19881994, was used. Detailed descriptions of the stratified cluster sampling strategy have been described elsewhere [8]. This survey gathered information regarding the health status of $\sim 40,000$ American individuals, aged $\geqslant 2$ months old with no preset upper age limit. In order to obtain reliable estimates of the health status of different population subgroups, younger children, older persons, Mexican-Americans and AfricanAmericans were sampled in large numbers. The overall 
response rate in the NHANES III was $82 \%(80 \%$ for Whites, $86 \%$ for Blacks, and $87 \%$ for Mexican-Americans) [9].

\section{Study population and outcome variables}

The analyses involved using data from the 18,825 adults aged $\geqslant 20$ yrs and who were interviewed in the NHANES III project. In this analysis two outcome variables, asthma and wheezing, were used. Current asthma (asthma) was defined as an affirmative response to the question "Has a doctor ever told you that you had asthma?" and "Do you still have asthma?" Wheezing was defined as an affirmative response to the question "Have you had wheezing or whistling in your chest at any time in the past 12 months?" Subjects who responded in the affirmative to the following question "Has a doctor ever told you that you had emphysema?" (item HAC1G in NHANES III, n=432) were excluded from the analysis.

\section{Independent variable selection}

Independent variables included in the analysis were selected based on risk factors reported in the literature, and classified into five broad conceptual categories: 1) demographic i.e. age, sex, race/ethnicity, urban/rural, and census region; 2) socioeconomic i.e. education and poverty income ratio; 3 ) indoor air quality based on the response to a limited number of questions on the use of a space heater, furnace, or oven to heat the home; 4) allergy, hay fever; and 5) other characteristics i.e. smoking history, body mass index (BMI), and family and household size.

\section{Statistical analysis}

Since the NHANES III uses a complex survey design, a statistical package (STATA statistical software; Stata Inc., College Station, TX), which allows users to incorporate sampling weights and compute sampling variances, was used for the analysis. Simple descriptive statistics were used to describe the study population, followed by univariate and multivariate analyses using logistic regression to explore the association between independent variables and the outcome variable. Separate univariate and multivariate models were built using asthma and wheezing as the outcome variable. All variables significant at $\mathrm{p}<0.1$ were considered for inclusion in the final model. Multiple logistic regression analysis was used to simultaneously adjust for the various independent variables. Estimated crude odds ratios (ORs), and adjusted ORs with their corresponding 95\% confidence intervals (CI) were calculated.

\section{Results}

Based on the study inclusion and exclusion criteria, a total of 18,393 study subjects aged $\geqslant 20$ yrs were included in the analysis. Table 1 describes the weighted percentage of the respondents by selected demographic and housing-related variables. The prevalence of asthma was $4.5 \%$, while wheezing was reported as $16.4 \%$. The prevalence of asthma and wheezing did not differ significantly across different age groups (table 2). When restricted to age group 20-44 yrs (as used in the ECRHS), the prevalence of asthma was $4.7 \%(95 \%$ CI $4.0-5.5)$ and the prevalence of wheezing was $17.5 \%(95 \% \mathrm{CI}$ 16.3-18.6).
Table 1.-Demographic and housing characteristics of study subjects aged $\geqslant 20$ yrs from the National Health and Nutrition Examination Survey III 1988-1994

\begin{tabular}{|c|c|c|}
\hline Variable & Unweighted n & Weighted $\%$ \\
\hline Subjects & $18395^{\#}$ & \\
\hline Male & 8536 & 47.3 \\
\hline Female & 9859 & 52.7 \\
\hline Age yrs & $44.0 \pm 0.41$ & \\
\hline $20-29$ & 3780 & 22.6 \\
\hline $30-39$ & 3585 & 24.5 \\
\hline $40-49$ & 2773 & 18.9 \\
\hline $50-59$ & 2001 & 12.3 \\
\hline$>60$ & 6256 & 21.7 \\
\hline \multicolumn{3}{|l|}{ Race/ethnicity } \\
\hline Non-Hispanic White & 7821 & 76.3 \\
\hline Non-Hispanic Black & 5010 & 11.1 \\
\hline Mexican-American & 4860 & 5.2 \\
\hline Other race/ethnic group & 704 & 7.4 \\
\hline \multicolumn{3}{|l|}{ Census region } \\
\hline North-east & 2686 & 20.8 \\
\hline Midwest & 3514 & 23.9 \\
\hline South & 7844 & 34.2 \\
\hline West & 4351 & 21.1 \\
\hline \multicolumn{3}{|l|}{ Year house built } \\
\hline Before 1946 & 4017 & 22.0 \\
\hline After 1946 & 12362 & 69.1 \\
\hline Missing values & 2016 & 8.9 \\
\hline \multicolumn{3}{|l|}{$\begin{array}{l}\text { Space heater or furnace } \\
\text { used to heat the home }\end{array}$} \\
\hline No & 3655 & 21.0 \\
\hline Yes & 14740 & 79.0 \\
\hline \multicolumn{3}{|l|}{$\begin{array}{l}\text { Stove or oven used to } \\
\text { heat the home }\end{array}$} \\
\hline No & 8595 & 46.7 \\
\hline Yes & 1434 & 7.8 \\
\hline Missing values & 8366 & 45.5 \\
\hline \multicolumn{3}{|l|}{ Pet Owner } \\
\hline No & 12457 & 58.6 \\
\hline Yes & 5876 & 41.4 \\
\hline
\end{tabular}

\#. n may not total to 18395 in some variables due to missing values; ${ }^{\text {}}$ : age is expressed as mean $\pm \mathrm{SE} ;{ }^{+}$: during the preceding 12 months.

Table 2. - Prevalence of current asthma and wheezing by age group

\begin{tabular}{lcc}
\hline Age yrs & Asthma & Wheezing \\
\hline $20-29$ & $4.7(3.7-5.8)$ & $17.6(15.4-19.8)$ \\
$30-39$ & $4.5(3.7-5.4)$ & $17.2(15.2-19.2)$ \\
$40-49$ & $5.4(3.8-6.7)$ & $17.3(15.2-19.5)$ \\
$50-59$ & $4.8(3.3-6.3)$ & $15.6(13.0-18.2)$ \\
$>60$ & $3.6(2.9-4.2)$ & $13.8(12.6-15.1)$ \\
\hline
\end{tabular}

Data are presented as weighted $\%(95 \%$ confidence interval).

An estimated $11.4 \%$ of the USA population were living below poverty level and an estimated $24.7 \%$ had $<12$ yrs of education (table 3). Approximately $28 \%$ of adults were current smokers. The estimated prevalence of obesity (defined as BMI $\geqslant 30$ ) among adults was 30\%. Mexican-Americans formed the largest ethnic group living below the poverty level. More than one-half also reported receiving $<12$ yrs of education (table 3).

Mexican-Americans exhibited the lowest prevalence of asthma $(2.9 \%)$ when compared with other race/ethnic groups. The prevalence of wheezing was highest among non-Hispanic 
Table 3. - Health and social characteristics by race/ethnicity in the National Health and Nutrition Examination Survey III adult study population 1988-1994

\begin{tabular}{|c|c|c|c|c|c|}
\hline & Total & $\begin{array}{l}\text { Non-Hispanic } \\
\text { White }\end{array}$ & $\begin{array}{l}\text { Non-Hispanic } \\
\text { Black }\end{array}$ & Mexican-American & $\begin{array}{l}\text { Other race/ethnic } \\
\text { group }\end{array}$ \\
\hline Subjects $n$ & 18393 & 7821 & 5010 & 4860 & 704 \\
\hline Asthma ${ }^{\#}$ & $4.5(4.0-5.1)$ & $4.7(4.0-5.3)$ & $5.1(4.3-5.8)$ & $2.9(2.4-3.4)$ & $3.5(1.7-5.3)$ \\
\hline Wheezing & $16.4(15.4-17.4)$ & $17.7(16.4-18.9)$ & $12.8(11.4-14.1)$ & $11.6(9.9-13.3)$ & $12.3(8.4-16.3)$ \\
\hline Hay fever & $11.9(11.0-12.8)$ & $13.2(12.1-14.3)$ & $9.6(8.7-10.5)$ & $5.3(4.1-6.4)$ & $7.4(5.1-9.7)$ \\
\hline Chronic bronchitis $^{+}$ & $5.7(5.2-6.2)$ & $6.3(5.7-6.9)$ & $4.7(3.9-5.6)$ & $3.1(2.6-3.6)$ & $2.9(1.2-4.6)$ \\
\hline Chronic cough & $8.7(8.1-9.4)$ & $9.9(9.1-10.7)$ & $5.4(4.8-5.9)$ & $4.7(3.8-5.6)$ & $4.9(2.7-7.0)$ \\
\hline Phlegm & $8.1(7.5-8.7)$ & $8.8(8.0-9.6)$ & $6.1(5.4-6.8)$ & $5.9(5.1-6.6)$ & $5.1(3.4-6.7)$ \\
\hline Shortness of breath & $22.1(20.6-23.6)$ & $22.3(20.4-24.2)$ & $22.7(21.5-24.0)$ & $19.9(18.3-21.4)$ & $20.8(15.9-25.8)$ \\
\hline Nasal or eye symptoms & $58.7(57.3-60.1)$ & $61.9(60.2-63.6)$ & $47.9(46.0-49.7)$ & $45.4(42.1-48.7)$ & $51.5(45.3-57.7)$ \\
\hline Below poverty & $11.4(10.0-12.9)$ & $7.3(6.1-8.5)$ & $25.5(22.4-28.7)$ & $30.7(27.4-33.9)$ & $19.3(10.9-27.6)$ \\
\hline Less than high school education ${ }^{+}$ & $24.7(22.9-26.6)$ & $20.1(18.1-22.1)$ & $32.0(29.6-34.3)$ & $58.4(55.0-61.8)$ & $38.4(29.8-46.9)$ \\
\hline Current smokers & $28.3(26.8-29.9)$ & $28.6(26.7-30.5)$ & $33.2(31.1-35.2)$ & $23.0(21.4-24.7)$ & $21.7(17.4-26.1)$ \\
\hline Past smokers & $25.2(24.0-26.3)$ & $27.7(26.4-28.9)$ & $16.1(14.7-17.6)$ & $20.1(18.8-21.5)$ & $16.3(13.3-19.3)$ \\
\hline \multicolumn{6}{|l|}{ BMI } \\
\hline$<18.5$ & $2.1(1.8-2.5)$ & $2.1(1.7-2.5)$ & $2.0(1.7-2.4)$ & $1.2(0.7-1.7)$ & $2.8(0.7-4.8)$ \\
\hline $18.5-24.9$ & $38.3(36.4-40.3)$ & $38.9(36.9-41.0)$ & $33.4(31.5-35.3)$ & $31.4(29.1-33.7)$ & $44.2(38.2-50.3)$ \\
\hline $25-29.9$ & $29.6(28.5-30.6)$ & $29.3(28.0-30.6)$ & $30.1(28.9-31.3)$ & $35.7(33.9-37.5)$ & $27.0(22.7-31.3)$ \\
\hline$\geqslant 30$ & $30.0(28.6-31.4)$ & $29.6(27.9-31.4)$ & $34.5(32.5-36.5)$ & $31.7(29.5-34.0)$ & $26.0(21.8-30.2)$ \\
\hline
\end{tabular}

Data are presented as weighted \% (95\% confidence interval). BMI: body mass index. ${ }^{*}$ : current asthma; ${ }^{\top}$ : self-reported, physiciandiagnosed hay fever; ${ }^{+}$: self-reported, physician-diagnosed chronic bronchitis.

Whites when compared with Mexican-Americans and AfricanAmericans (table 3). The estimated prevalences of other respiratory conditions and symptoms were significantly lower among non-Hispanic Blacks and Mexican-Americans than nonHispanic Whites (table 3).

The prevalence of asthma was significantly higher among females $(5.4 \%, 95 \%$ CI $4.6-6.2)$ than males $(3.6 \%, 95 \%$ CI 2.8-4.4). No differences, however, were observed for wheezing. The prevalence of asthma and wheezing did not vary significantly by region. However, when the data were stratified by race/ethnicity, an interesting pattern was observed. MexicanAmericans living in the south region of the USA had the lowest prevalence of asthma $(1.5 \%, 95 \%$ CI 1.0-2.1) while the other race/ethnicity group (which included other Hispanics and Asian populations) had the highest prevalence in the Northeast $(6.5 \%, 95 \%$ CI $1.1-1.9)$ and Midwest regions $(8.8 \%$, 95\% CI 3.2-14.4). Mexican-Americans in the Northeast had the highest prevalence of wheezing (19.0\%, 95\% CI 9.2-28.8), and those in the Midwest exhibited the lowest prevalence

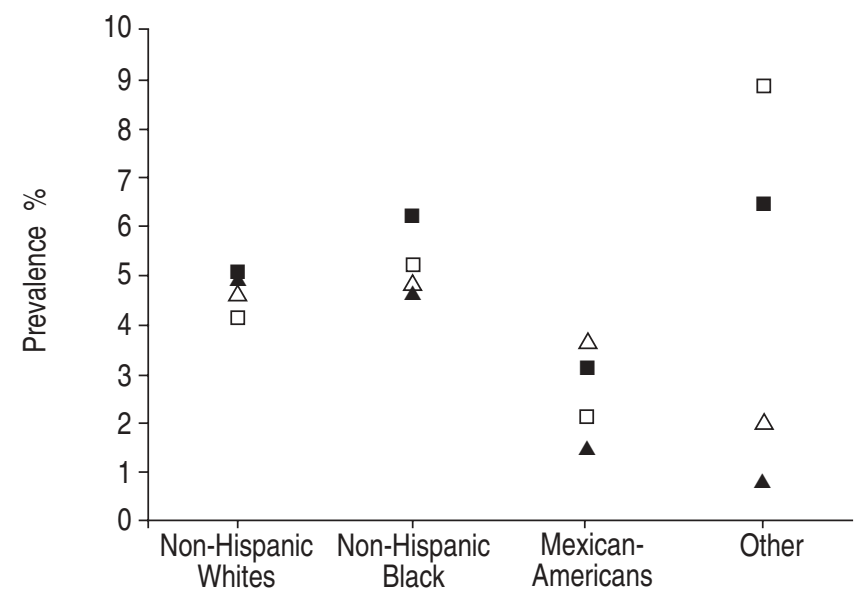

Fig. 1.-Estimated prevalence of asthma across four regions of the USA by race/ethnicity in the National Health and Nutrition Examination Survey III adult study population, 1988-1994. [: north-east; $\square$ : Midwest; $\boldsymbol{\Lambda}$ : south; $\triangle$ : west.
(8.6\%, 95\% CI 4.7-12.4). The other race/ethnic group had the highest prevalence of wheezing in the Midwest region $(21.7 \%$, 95\% CI 6.2-37.1) (figs 1 and 2).

The estimated crude and adjusted ORs with $95 \%$ CIs for associations between independent risk factors and asthma and self-reported wheezing in the previous 12 months are presented in table 4. Mexican-Americans were 0.61-times less likely to report asthma when compared with non-Hispanic Whites. Female sex, living below poverty, low-education level, living in an older house, pet ownership, lifetime diagnosis of physician-diagnosed hay fever (hay fever) and obesity were all significantly associated with asthma. Current and past smoking history did not show any significant associations with asthma.

Race/ethnicity was an important risk factor for wheezing. Mexican-Americans (adjusted $\mathrm{OR}=0.55$ ) and non-Hispanic blacks (adjusted $\mathrm{OR}=0.58$ ) showed a significantly lower risk for wheezing. Living in the west census region of the USA did not show a significant association in the univariate analysis.

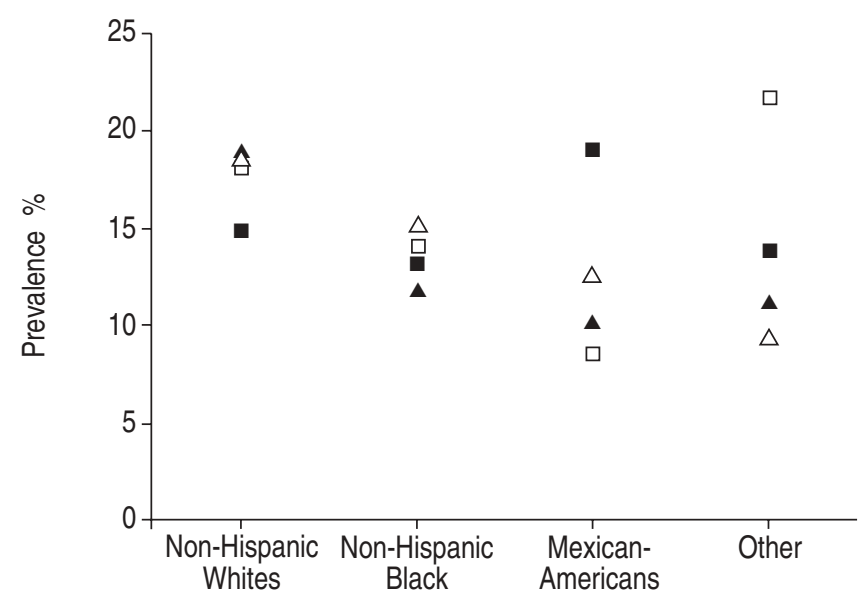

Fig. 2. - Estimated prevalence of wheezing across four regions of the USA by race/ethnicity in the the National Health and Nutrition Examination Survey III adult study population,1988-1994. $\mathbf{\square}$ : northeast; $\square$ : Midwest; $\boldsymbol{\Lambda}$ : south; $\triangle$ : west. 
Table 4. - Estimated crude and adjusted odds ratios (OR) and 95\% confidence intervals (CI) using current asthma and wheezing in the previous12 months as an outcome in the National Health and Nutrition Examination Survey 1988-1994

\begin{tabular}{|c|c|c|c|c|}
\hline \multirow[t]{2}{*}{ Variables } & \multicolumn{2}{|c|}{ Asthma } & \multicolumn{2}{|c|}{ Wheezing } \\
\hline & Crude & Adjusted & Crude & Adjusted \\
\hline \multicolumn{5}{|l|}{ Race/ethnicity } \\
\hline Non-Hispanic White & 1.00 & 1.00 & 1.00 & 1.00 \\
\hline Non-Hispanic Black & $1.09(0.89-1.34)$ & $1.09(0.88-1.36)$ & $0.68(0.60-0.78)$ & $0.58(0.49-0.67)$ \\
\hline Mexican-American & $0.61(0.48-0.77)$ & $0.61(0.45-0.84)$ & $0.61(0.51-0.73)$ & $0.55(0.44-0.68)$ \\
\hline Other & $0.74(0.27-0.43)$ & $0.83(0.48-1.44)$ & $0.67(0.44-0.97)$ & $0.72(0.47-1.09)$ \\
\hline Male & 1.00 & 1.00 & 1.00 & 1.00 \\
\hline Female & $1.53(1.17-2.01)$ & $1.48(1.09-2.01)$ & $1.02(0.89-1.16)$ & $1.13(0.97-1.32)$ \\
\hline \multicolumn{5}{|l|}{ Census region } \\
\hline North-east & & & 1.00 & 1.00 \\
\hline Midwest & & & $1.26(0.99-1.60)$ & $1.23(0.96-1.59)$ \\
\hline South & & & $1.17(0.96-1.42)$ & $1.17(0.96-1.43)$ \\
\hline West & & & $1.13(0.94-1.37)$ & $1.24(1.02-1.51)$ \\
\hline \multicolumn{5}{|l|}{ Poverty income ratio } \\
\hline At or above poverty & 1.00 & 1.00 & 1.00 & 1.00 \\
\hline Below poverty & $1.58(1.16-2.15)$ & $1.44(1.06-1.97)$ & $1.35(1.12-1.61)$ & $1.35(1.12-1.63)$ \\
\hline \multicolumn{5}{|l|}{ Education } \\
\hline High school & 1.00 & 1.00 & 1.00 & 1.00 \\
\hline$<12$ yrs & $1.29(1.04-1.61)$ & $1.63(1.25-2.13)$ & $1.18(1.03-1.35)$ & $1.17(0.99-1.38)$ \\
\hline \multicolumn{5}{|l|}{ Year house built } \\
\hline After 1946 & 1.00 & 1.00 & & \\
\hline Before 1946 & $1.38(1.07-1.79)$ & $1.30(1.00-1.69)$ & & \\
\hline Missing & $1.03(0.74-1.42)$ & $0.97(0.66-1.41)$ & & \\
\hline \multicolumn{5}{|l|}{ Use of stove/oven } \\
\hline No & & & 1.00 & 1.00 \\
\hline Yes & & & $1.45(1.09-1.94)$ & $1.35(0.94-1.93)$ \\
\hline \multicolumn{5}{|l|}{ Smoking status } \\
\hline Nonsmokers & 1.00 & 1.00 & 1.00 & 1.00 \\
\hline Current smokers & $1.28(0.99-1.64)$ & $1.27(0.95-1.70)$ & $3.48(2.96-4.08)$ & $3.62(3.00-4.37)$ \\
\hline Past smokers & $1.11(0.85-1.47)$ & $1.19(0.84-1.69)$ & $1.38(1.16-1.63)$ & $1.39(1.16-1.67)$ \\
\hline \multicolumn{5}{|l|}{ Pet ownership } \\
\hline No & 1.00 & 1.00 & & \\
\hline Yes & $1.45(1.20-1.74)$ & $1.37(1.09-1.73)$ & & \\
\hline \multicolumn{5}{|l|}{ Hay fever } \\
\hline No & 1.00 & 1.00 & 1.00 & 1.00 \\
\hline Yes & $5.21(3.99-6.79)$ & $5.45(4.18-7.09)$ & $2.11(1.85-2.40)$ & $2.36(2.05-2.71)$ \\
\hline \multicolumn{5}{|l|}{ BMI } \\
\hline$<18.5$ & $1.26(0.60-2.68)$ & $1.16(0.50-2.69)$ & $1.24(0.81-1.88)$ & $1.17(0.72-1.90)$ \\
\hline $18.5-24.9$ & 1.00 & 1.00 & 1.00 & 1.00 \\
\hline $25-29.9$ & $0.83(0.59-1.18)$ & $0.96(0.68-1.35)$ & $1.03(0.91-1.18)$ & $1.21(1.04-1.40)$ \\
\hline$\geqslant 30$ & $1.33(1.01-1.76)$ & $1.43(1.07-1.92)$ & $1.30(1.12-1.51)$ & $1.52(1.29-1.79)$ \\
\hline
\end{tabular}

Data are presented as OR $(95 \% \mathrm{CI}) .{ }^{*}$ : the poverty income ratio was computed as a ratio of the annual family income as numerator and the poverty threshold, the age of the family reference person and the calendar year, in which the family was interviewed, as a denominator; ${ }^{\uparrow}$ : due to the large number of missing values, these were coded as a category to be in included in the model. Adjusted ORs were obtained by simultaneously adjusting all other variables in the model plus the age.

However, when adjusted for other variables in the model a statistically significant association was observed (adjusted $\mathrm{OR}=1.24$ ). Use of a stove/oven for heating by the residence in the previous 12 months showed a $45 \%$ increased odds of wheezing in the univariate analysis. This point estimate decreased when adjusted for other variables in the final model, but was retained due to its strong univariate effect. There were no significant differences in the prevalence of asthma and wheezing for the use of stove/ovens between male and females. Owning a pet was also significant in the univariate analysis, however, the effect was diluted and became nonsignificant when adjusted for other variables in the model. A moderate association of BMI with wheezing was observed for both underweight and obese individuals in the univariate analysis. However, the OR increased significantly from 1.30 to 1.52 for obese individuals only. When stratified by sex, no significant differences in the prevalence of asthma and wheezing for obesity were observed. A strong association of wheezing with past and current smoking history was observed in this analysis. Living below the poverty level, and lifetime history of hay fever were also significantly associated with wheezing.

\section{Discussion}

The major strength of the present analysis is that it is based on a large representative national sample of the USA population. Few population-based studies have addressed the prevalence of asthma among adults in the USA.

The results show that the prevalence of current asthma was $4.5 \%$ and the prevalence of wheezing was $16.5 \%$. Previously reported prevalence rates of asthma in adults have ranged from below $3 \%$ to over $20 \%[2,3,10,11]$. In the NHANES II, TURKELTAUB and GERGEN [11] reported a prevalence of $6.9 \%$ and 9.2\% among Whites and Blacks, respectively, based on 
self-reported physician diagnosis of asthma. JANSON et al. [3] in a recent review of ECRHS data compared geographical variation in the prevalence of asthma and asthma symptoms in 22 countries. The median prevalence of current asthma was $4.5 \%$ (range 2.0-11.9) similar to the results found in this study. In the ECRHS, asthma prevalence was generally higher in English-speaking countries. The median prevalence of wheezing was $20.7 \%$ (range 4.1-32.0), i.e. slightly higher than what was found in the present study. However, it is difficult to directly compare prevalence rates observed in this study with other reports due to the use of different populations and case definitions.

There was a significantly higher prevalence of asthma, but not wheezing, among females in this study. Asthma and wheeze are generally reported to be higher among male children, but the trend usually reverses around puberty [3, 12-14]. It has been suggested that the higher prevalence rates observed among females could partly be due to their smaller airway calibre size [13]. Alternately, it may also reflect the tendency among physicians to diagnose a respiratory condition as asthma in females and chronic obstructive pulmonary disorder (COPD) in males [10].

Contrary to earlier reports [10, 15] non-Hispanic Blacks did not have a higher risk of asthma in this study. Moreover, nonHispanic Blacks showed less wheezing compared with nonHispanic Whites, and Mexican-Americans showed the lowest risk of asthma and wheezing compared with the other groups. Previous studies from California, New Mexico and Arizona have found a lower risk of asthma and other respiratory diseases among Mexican-American adults [6, 16]. Results from the Hispanic Health and Nutrition Examination Survey suggested that Puerto Rican children have the highest prevalence of asthma (20.1\%) compared with Mexican-Americans $(4.5 \%)$, non-Hispanic Whites $(6.4 \%)$ and non-Hispanic Blacks $(9.1 \%)$ [15]. It has been argued that the lower risk among Mexican-Americans can be explained by differences in socioeconomic status (SES) and access to healthcare. However, in the present study, rates remained significantly lower among Mexican-Americans, even after controlling for SES and other confounding factors.

There were no overall differences in prevalence of asthma and wheezing across regions, although a variation across different race/ethnic groups by region was observed. Earlier reports indicated that the morbidity and mortality of asthma among Puerto Rican Hispanics is highest in the north-eastern USA [17]. The 1988 National Health Interview Survey also found the highest prevalence of asthma among children younger than $18 \mathrm{yrs}$ of age in the north-eastern region of the USA [18]. This study found the highest prevalence of asthma was among the other race/ethnic groups and the highest prevalence of wheezing among Mexican-Americans to be in the north-eastern USA. In the NHANES III, Hispanics who were not self-reported as Mexican-American were included in the other race/ethnic groups category and these should have included Puerto Ricans. Therefore, the possibility of misclassification of Puerto Ricans as Mexican-Americans is not likely to explain the high prevalence of wheezing observed in this region. A variety of factors could explain the decreased risk of asthma among Mexican-Americans. These include genetic/biological factors, differences in health beliefs and behaviours among Hispanic subgroups, protective psychosocial effects, consumption of a diet rich in fruit and vegetables, and differences in migration pattern, favouring a "healthy migrant effect" [17, 19].

The majority of the relatively few studies that have looked at the relationship between asthma and poverty in adults have found an association between low SES and asthma, as was the case in this study. This was also true in the two previous rounds of the NHANES survey $[4,10,11]$. Persistent wheeze was also found to be associated with poverty among children, based on parental social class [20]. In contrast, MIELCK et al. [21] in a review of 24 studies found either no association or negative association of SES with asthma. However, in their own study, the authors found a strong association between poverty and severe asthma (OR 2.37, 95\% CI 1.28-4.41). Differences in the measurement of SES and definitions of poverty may be partly responsible for the inconsistent findings.

In this present study, the prevalence of asthma and/or wheezing was affected by various environmental factors. Both current and past smoking, were strong predictors of wheezing, but not of asthma, compared with never-smokers, this was most marked in current smokers. These results did not change when the analysis was restricted to subjects aged 20-44 yrs; this finding is consistent with that of the ECRHS [3]. The relationship between smoking and asthma has been a subject of interest and conflicting findings. Thus, several studies have reported an association between smoking and asthma and/or wheezing [3, 22, 23], but others have not $[10,24$, 25]. Although the harmful effects of maternal smoking on the respiratory system of developing foetuses and children have been well documented [26], no clear cause and effect relationship between smoking and asthma in adults has been established. Cigarette smoke is likely to induce increased permeability of respiratory epithelium, which may result in increased "trafficking" of allergens and other inflammatory cells to submucosal cells resulting in allergic inflammation of the airways [27].

The use of space heaters, furnaces or gas stoves may affect indoor humidity levels, which might indirectly contribute to the growth of house dust mite, especially when malfunctioning. They can also generate oxides of nitrogen, which are oxidant gases and indoor air pollutants. Studies performed in some European countries [28, 29], but not in the USA [30], have reported increased risk of wheezing among females using gas cookers. In the ECRHS, although a positive association was found with gas cooking, this was limited to females and there was considerable variation among countries [3]. The results from this study are consistent with those of earlier USA-based studies; a moderate associations between the use of a gas stove and wheezing was observed only in the univariate analysis. No quantitative measurements of indoor pollutants or allergens were made in NHANES III, and the questions relating to indoor air were narrow in their scope; these are important limitations to the study's findings. The relationship of these findings to housing characteristics and home heating, ventilation and air conditioning should be further explored.

Previously, pet ownership has been linked to asthma and asthma symptoms in children and adults [31] as found in this study. The magnitude of the association with wheezing, however, was diluted and became nonsignificant after simultaneously adjusting for other confounders in the model. One possible reason for this diminished effect could be that subjects with wheezing avoided pets and this observed association has been underestimated. Hay fever is a well-established risk factor for asthma and wheezing, and the current findings are consistent with this.

Until recently, few epidemiological studies have looked at the relationship between obesity and asthma. However, positive associations have been found in studies of nurses [32], children [4], and British adults [33], and the results from the present study are similar. Individuals with asthma tend to be overweight [4] and obese individuals tend to have lower pulmonary function tests [34]. Due to the cross-sectional nature of the study it may be argued that the higher BMI is a result of asthma, due to weight gain from corticosteroid use or avoidance of physical activity. Obese individuals are 
generally sedentary, which may result in increased time spent indoors, thereby predisposing them to indoor air allergens, environmental tobacco smoke, and dust mite antigens. Obesity also predisposes to gastro-oesophageal reflux disease, which may induce asthmatic symptoms [35]. Given the current concern regarding obesity as a public health problem in the USA, a more detailed evaluation of this association is definitely warranted.

The major limitation of this analysis is the cross-sectional nature, which precludes establishing temporal relationships or inferring causality. Asthma is frequently misdiagnosed, especially among the elderly and very young. With the absence of any objective measure to test airway hyperresponsiveness (e.g. histamine or methacholine challenge tests) the possibility of misclassification cannot be ruled out. However, any such misclassification would likely be nondifferential. In the present study, all subjects with emphysema in the final analysis were removed but those who had responded affirmatively to the question on ever having been diagnosed as having chronic bronchitis (item HAC1F in the NHANES III) were retained. This decision was made because chronic bronchitis is a symptom-based diagnosis and although the authors recognise that the main risk factor for "true" chronic bronchitis is cigarette smoking, it is also true that asthma may present with chronic cough as its only symptom (coughvariant asthma). Consequently, there is a certain degree of overlap between the two conditions in adults. Interestingly, when a subgroup analysis was performed on persons who indicated having a diagnosis of chronic bronchitis (but not emphysema) and these respondents were stratified by smoking status, a higher prevalence of current asthma was observed among nonsmokers $(22.3 \%, 95 \%$ CI $15.8-28.8)$, past smokers (24.0\%, 95\% CI 14.8-33.1), and current smokers $(24.7 \%, 95 \%$ CI 17.5-31.8) with chronic bronchitis. This would support the impression that there is some overlap (possibly misclassification) between chronic bronchitis and asthma, but that smoking status does not significantly impact the prevalence of asthma in these persons. However, when the prevalence of wheezing in the previous 12 months was examined in the same subgroup of chronic bronchitis subjects, by smoking status, the breakdown was as follows: nonsmokers $(45.4 \%, 95 \%$ CI 36.8-53.9), past smokers $(43.7 \%, 95 \%$ CI 33.4-54.0) and current smokers $(62.9 \%, 95 \%$ CI 55.8-69.9). Given the disparity between the findings for asthma and wheezing, it is possible that wheezing in current smokers reflects a condition other than asthma (e.g. undiagnosed COPD, or chronic obstructive bronchitis), leading to some misclassification of asthma status.

In summary, this cross sectional analysis of the National Health and Nutrition Examination III dataset showed that race/ethnicity, female sex, socioeconomic status, smoking, obesity, hay fever and pet ownership are important risk factors for asthma and wheezing. Differences in prevalence of asthma and wheeze were observed for USA regions when stratified by race/ethnicity. Mexican-Americans are less likely to report asthma and wheeze irrespective of their socioeconomic and health insurance status. No significant associations were found with a few surrogate measures of indoor air quality.

\section{References}

1. Anderson HR. Is the prevalence of asthma changing? Arch Dis Child 1989; 64: 172-175.

2. Mannino DM, Homa DM, Pertowski CA, et al. Surveillance for asthma-United States, 1960-1995. Mor Mortal Wkly Rep CDC Surveill Summ 1998; 47: 1-27.

3. Janson C, Anto J, Burney P, et al. The European Community
Respiratory Health Survey: what are the main results so far? Eur Respir J 2001; 18: 598-611.

4. Schwartz J, Weiss ST. Dietary factors and their relation to respiratory symptoms. The Second National Health and Nutrition Examination Survey. Am J Epidemiol 1990; 132: 67-76.

5. Burney PG, Chinn S, Britton JR, Tattersfield AE, Papacosta AO. What symptoms predict the bronchial response to histamine? Evaluation in a community survey of the bronchial symptoms questionnaire (1984) of the International Union Against Tuberculosis and Lung Disease. Int $J$ Epidemiol 1989; 18: 165-173.

6. Samet JM, Coultas DB, Howard CA, Skipper BJ. Respiratory diseases and cigarette smoking in a Hispanic population in New Mexico. Am Rev Respir Dis 1988; 137: 815-819.

7. Venables KM, Farrer N, Sharp L, Graneek BJ, Newman Taylor AJ. Respiratory symptoms questionnaire for asthma epidemiology: validity and reproducibility. Thorax 1993; 48: 214-219.

8. National Center for Health Statistics. Sample Design: Third National Health and Nutrition Examination Survey. Vital and health statistics series 2 (113). DHHS publication No. (PHS) 92-1387 (GPO no. 017-022-01166-2). Hyattsville, NCHS, 1992.

9. National Health and Nutrition Examination Survey (NHANES) III. Data CD dated October 1996: Analytic and Reporting Guidelines. Table A.6. NHANES III, 1988-94.

10. McWhorter WP, Polis MA, Kaslow RA. Occurance, predictors, and consequences of adult asthma in NHANES I and followup survey. Am Rev Respir Dis 1989; 139: 721-724.

11. Turkeltaub PC, Gergen PJ. Prevalence of upper and lower respiratory conditions in the US population by social and environmental factors: data from the second National Health and Nutrition Examination Survey, 1976 to 1980 (NHANES II). Ann Allergy 1991; 67: 147-154.

12. Sunyer J, Anto JM, Kogevinas M, et al. Risk factors for asthma in young adults. Spanish Group of the European Community Respiratory Health Survey. Eur Respir J 1997; 10: 2490-2494.

13. de Marco R, Locatelli F, Sunyer J, Burney P. Differences in incidence of reported asthma related to age in men and women. A retrospective analysis of the data of the European Respiratory Health Survey. Am J Respir Crit Care Med 2000; 162: 68-74.

14. Basagana X, Sunyer J, Zock J, et al. Incidence of asthma and its determinants among adults in Spain. Am J Respir Crit Care Med 2001; 164: 1133-1137.

15. Carter-Pokras OD, Gergen PJ. Reported asthma among Puerto Rican, Mexican-American, and Cuban children, 1982 through 1984. Am J Public Health 1993; 83: 580-582.

16. Samet JM, Schrag SD, Howard CA, Key CR, Pathak DR. Respiratory disease in a New Mexico population sample of Hispanic and non-Hispanic whites. Am Rev Respir Dis 1982; 125: $152-157$.

17. Homa DM, Mannino DM, Lara M. Asthma mortality in U.S. Hispanics of Mexican, Puerto Rican, and Cuban heritage, 1990-1995. Am J Respir Crit Care Med 2000; 161: 504-509.

18. Taylor WR, Newacheck PW. Impact of childhood asthma on health. Pediatrics 1992; 90: 657-662.

19. Liao Y, Cooper RS, Cao G, et al. Mortality patterns among adult Hispanics: findings from the NHIS, 1986 to 1990. Am J Public Health 1998; 80: 227-232.

20. Duran-Tauleria E, Rona RJ. Geographical and socioeconomic variation in the prevalence of asthma symptoms in English and Scottish children. Thorax 1999; 54: 476-481.

21. Mielck A, Reitmeir P, Wjst M. Severity of childhood asthma by socioeconomic status. Int J Epidemiol 1996; 25: 388-393.

22. Flodin U, Jonsson P, Ziegler J, Axelson O. An epidemiologic study of bronchial asthma and smoking. Epidemiology 1995; 6: 503-505.

23. Kaplan BA, Mascie-Taylor CG. Smoking and asthma among 23-year-olds. J Asthma 1997; 34: 219-226. 
24. Sunyer J, Anto JM, Kogevinas M, Soriano JB, Tobias A, Munoz A. Smoking and bronchial responsiveness in nonatopic and atopic young adults. Spanish Group of the European Study of Asthma. Thorax 1997; 52: 235-238.

25. Higgins MW, Keller JB, Metzner HL. Smoking, socioeconomic status, and chronic respiratory disease. Am Rev Respir Dis 1977; 116: 403-410.

26. Gern JE, Lemanske RF Jr, Busse WW. Early life origins of asthma. J Clin Invest 1999; 104: 837-843.

27. Floreani AA, Rennard SI. The role of cigarette smoke in the pathogenesis of asthma and as a trigger for acute symptoms Curr Opin Pulm Med 1999; 5: 38-46.

28. Samet JM, Speizer FE. Assessment of health effects in epidemiologic studies of air pollution. Environ Health Perspect 1993; 101: Suppl. 4, 149-154.

29. Burr ML, Anderson HR, Austin JB, et al. Respiratory symptoms and home environment in children: a national survey. Thorax 1999; 54: 27-32.
30. Jarvis D, Chinn S, Luczynska C, Burney P. Association of respiratory symptoms and lung function in young adults with use of domestic gas appliances. Lancet 1996; 347: 426-431.

31. Leynaert B, Liard R, Bousquet J, Mesbah H, Neukirch F Gas cooking and respiratory health in women. Lancet 1996 347: 1052-1053.

32. Camargo CA Jr, Weiss ST, Zhang S, Willett WC, Speizer FE. Prospective study of body mass index, weight change, and risk of adult-onset asthma in women. Arch Intern Med 1999; 159: 2582-2588.

33. Shaheen SO, Sterne JA, Montgomery SM, Azima H. Birth weight, body mass index and asthma in young adults. Thorax 1999; 54: 396-402.

34. Ray CS, Sue DY, Bray G, Hansen JE, Wasserman K. Effects of obesity on respiratory function. Am Rev Respir Dis 1983; 128: 501-506.

35. Field SK. Gastroesophageal reflux and asthma: can the paradox be explained? Can Respir J 2000; 7: 167-176. 